\title{
Correction to: Introduction: Current Challenges of Global History in East Asian Historiographies
}

\author{
Manuel Perez Garcia
}

\section{Correction to:}

Chapter 1 in: M. Perez Garcia and L. de Sousa (eds.), Global History and New Polycentric Approaches, Palgrave Studies in Comparative Global History, https://doi.org/10.1007/978-981-10-4053-5_1

The original version of the book was revised deleting the author name "Harriet Zurndorfer", referring to the retracted Chapter 4, in Chapter 1. The correction chapter and the book have been now updated with the change.

The updated version of this chapter can be found at https://doi.org/10.1007/978-981-10-4053-5_1 